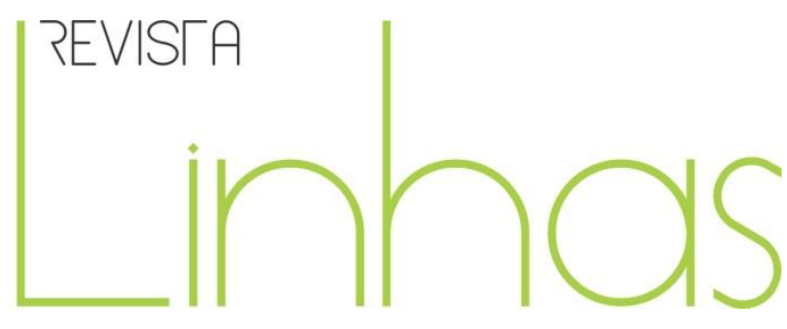

\title{
O programa Future-se e o empresariamento da educação superior
}

\begin{abstract}
Resumo
Recentemente, o Ministério da Educação (MEC) anunciou mais uma proposta privatizante com significativo impacto na oferta e garantia do Ensino Superior público, trata-se do Programa Universidades e Institutos Empreendedores e Inovadores - Future-se, lançado em julho de 2019. Esse programa é o objeto desta investigação, portanto este artigo tem por objetivo analisar esta política educacional com intuito de compreendê-la como mais uma das medidas que aprofundam o caráter privatista e empresarial da educação pública brasileira. Como procedimento metodológico, faremos uma análise documental do Programa Future-se com base na minuta de Projeto de Lei apresentada pelo Governo Federal ao Congresso Nacional. É possível identificar que dois conceitos-chave do projeto - inovação e empreendedorismo - se tornaram slogans das políticas educacionais capitalistas em meio à sua mais profunda crise. A partir dessas premissas e fundamentos, a análise sobre o programa passa, necessariamente, por compreender que há uma determinação explícita do mercado sobre a vida. Ao invés de pensar a educação voltada a enfrentar os problemas sociais, as demandas de vida da população e a formação humana de qualidade de cada sujeito, as políticas educacionais em curso definem os interesses empresariais, de lucratividade de poucos e as demandas econômicas como as bases fundantes dos projetos educacionais; não é a educação contribuindo para a formação humana, é o mercado capitalista determinando as mercadorias humanas de que necessita.
\end{abstract}

Palavras-chave: Educação e Estado. Empreendedorismo. Privatização na educação.

\author{
Giovanni Frizzo \\ Universidade Federal de Pelotas - \\ UFPel - Pelotas/RS - Brasil \\ gfrizzo2@gmail.com \\ Leonardo Silveira \\ Universidade Federal de Pelotas - \\ UFPel - Pelotas/RS - Brasil \\ leo.pf.ef@gmail.com
}

\footnotetext{
Para citar este artigo:

FRIZZO, Giovanni; SILVEIRA, Leonardo. O programa Future-se e o empresariamento da educação superior.

Revista Linhas. Florianópolis, v. 21, n. 46, p. 91-116, maio/ago. 2020.
} 


\title{
The Program Future-se and the Higher Education entrepreneurship
}

\begin{abstract}
Recently, the Ministry of Education (MEC) announced yet another privatizing proposal with a significant impact on the offer and guarantee of public higher education, this is the Entrepreneur and Innovative Universities and Institutes Program - Future-se, launched in July 2019. This program is the object of this investigation, so this article aims to analyze this educational policy in order to understand it as one of the measures that deepen the privatist and entrepreneurial character of Brazilian public education. As a methodological procedure, we will make a documentary analysis of the Future-se Program based on the draft Bill submitted by the Federal Government to the National Congress. It is possible to identify that two key concepts of the project - innovation and entrepreneurship - have become slogans of capitalist educational policies in the midst of its deepest crisis. Based on these premises and fundamentals, the analysis of the program necessarily involves understanding that there is an explicit determination of the market on life. Rather than thinking about education aimed at facing social problems, the population's life demands and the quality human training of each subject, the ongoing educational policies define the business interests, profitability of a few and economic demands as the bases founders of educational projects; it is not education contributing to human formation, it is the capitalist market determining the human goods it needs.
\end{abstract}

Keywords: Education policy. Entrepreneurship. Privatization of education. 
Em meio ao aprofundamento da crise do capitalismo em escala global, as medidas que os governos têm adotado em todo o mundo se referem, especialmente, ao que chamamos de assalto ao fundo público, ou seja, como forma de retomada dos patamares de lucratividade do capital, os setores empresariais articulados aos Estados implementam políticas que têm por centralidade a transformação dos direitos sociais em capital. Também chamado de Ajuste Fiscal, o que temos acompanhado é que esses ajustes se refletem em processos de privatização de todos os direitos sociais e patrimônio nacional.

As diferentes formas de reformas trabalhistas, previdenciárias, fiscais etc, representam a diminuição de investimentos públicos e ampliação da inserção privada na oferta de serviços e direitos, tais como: educação, saúde, previdência etc. Compreendemos que a adoção de tais medidas circunscrevem-se na política ultra-liberal que representa a destinação de orçamentos estatais para fins privados - tais como o mecanismo das dívidas públicas, privatizações, isenções/renúncias fiscais e cortes orçamentários em políticas sociais - é uma das principais medidas que vêm sendo adotadas por organismos internacionais e governos atrelados à perspectivas de recuperação de taxas de lucro de grandes corporações empresariais (FRIZZO, 2019).

No Brasil, desde o início da atual década, convivemos com um conjunto de políticas educacionais de caráter privatista e que beneficiam as corporações de empresas educacionais privadas. Nesse quadro de mercantilização da educação, temos recentemente o anúncio de mais uma medida privatizante com significativo impacto na oferta e garantia do Ensino Superior público, trata-se do Programa Universidades e Institutos Empreendedores e Inovadores - Future-se, lançado pelo Ministério da Educação (MEC) em julho de 2019. Esse programa é o objeto desta investigação, portanto este artigo tem por objetivo analisar essa política educacional com intuito de compreendê-la como mais uma das medidas que aprofundam o caráter privatista e empresarial da educação pública brasileira. 
De acordo com as informações oficiais da página do programa no Portal do MEC', o programa Future-se busca "o fortalecimento da autonomia administrativa, financeira e da gestão das universidades e institutos federais. Essas ações serão desenvolvidas por meio de parcerias com organizações sociais". O programa se divide em três eixos: a) pesquisa, desenvolvimento tecnológico e inovação; b) empreendedorismo; c) internacionalização. Cada um desses eixos tem objetivos específicos e serão matéria de análise em seção deste artigo.

Apesar do lançamento do programa ter sido em julho de 2019, diferentes setores da sociedade avaliaram negativamente a proposta que sequer havia sido discutida com as próprias instituições de ensino interessadas antes de sua divulgação. Isso fez com que o MEC reformulasse alguns pontos do programa e lançasse a nova versão em outubro de 2019, com algumas modificações específicas, mantendo o caráter geral e o objetivo principal do programa que é: dar maior autonomia financeira a universidades e institutos por meio do fomento à captação de recursos próprios e ao empreendedorismo (MEC, 2019).

Para este estudo, utilizaremos a versão reformulada como base de referência para a análise, embora compreendamos que o conteúdo geral do programa não se modificou e as alterações expostas na segunda versão seguem a mesma perspectiva de empresariamento da educação da primeira versão. Apesar de ter sido anunciada em outubro de 2019 e apresentada pelo secretário de Educação Superior (SESu) do MEC, Arnaldo Barbosa, em reunião com a Associação Nacional dos Dirigentes de Instituições Federais de Ensino Superior (ANDIFES), o projeto de lei só foi publicado no Diário Oficial da União (DOU) em 3 de janeiro de $2020^{2}$. A versão que analisaremos neste artigo é a que foi apresentada aos reitores e reitoras das Universidades Federais na reunião com a ANDIFES e que foi amplamente publicizada pelas instituições 3 .

\footnotetext{
1 Disponível em: <http://portal.mec.gov.br/busca-geral/12-noticias/acoes-programas-e-projetos637152388/78351-perguntas-e-respostas-do-future-se-programa-de-autonomia-financeira-do-ensinosuperior>. Acesso em: 24 mar. 2020.

${ }^{2}$ Conferir em: <http://www.in.gov.br/en/web/dou/-/despacho-236403674>.

3 Conferir em: <https://www.ufsm.br/wp-content/uploads/2019/10/Minuta-de-Anteprojeto-de-Lei-Future-seGT-Portaria-1701-16-10-2019.pdf>.
} 
Como procedimento metodológico, faremos uma análise documental da política educacional com base em Shiroma, Campos e Garcia (2005), em que concordamos que para analisar a política é preciso ter como base não somente a redação escrita, mas também os conceitos, o conteúdo e os discursos presentes nos documentos de política educacional. Na perspectiva de compreender a política, a redação do documento é ponto de partida em que "tomamos os textos como produtos e produtores de orientações políticas. Os sentidos não são dados nos documentos, são produzidos; estão aquém e além das palavras que os compõem." (SHIROMA; CAMPOS; GARCIA, 2005, p. 427).

Nesta análise da política, utilizaremos como documento principal a Minuta do projeto de lei publicada no DOU conforme citado acima. Também utilizaremos como fonte de levantamento de dados a página do programa no Portal do MEC, que inclui informações adicionais e entrevistas do Ministro da Educação, Abraham Weintraub, que explicitam os sentidos e significados dessa política educacional cujo projeto de lei ainda tramita internamente no Congresso Nacional. Importante mencionar que o projeto tem ampla rejeição nas Universidades Federais, através de notas das administrações ou decisões de conselhos superiores das instituições, observam-se variadas críticas ao programa e sua implementação, neste momento, ainda não se efetivou.

A análise dos dados será feita em dois momentos: no primeiro, faremos um levantamento de termos-chave presentes no documento, considerando a sua incidência de utilização, bem como da articulação com as finalidades do Programa que expressam, em última análise, slogans da política educacional em tela. Esses slogans visam criar aquilo que Shiroma e Santos (2014, p. 22) chamaram de "construção do consentimento ativo". Com base em Gramsci e Harvey, a autora e o autor deste afirmam que "a construção do consentimento ativo é realizada com a produção de um aparato conceitual que encontra apoio na sociedade”. E que, "o uso cotidiano de alguns conceitos pode dar a falsa impressão de que são naturais e inevitáveis, que constituem o fazer cotidiano e, com isso, gerar a conformação." (SHIROMA, SANTOS, 2014, p. 22). Fairclough (2001, p. 128), ao abordar a análise de discurso em políticas, reforça essa compreensão ao afirmar que "tal processo de naturalização é essencial para estabelecer novas hegemonias na esfera do discurso". 
Em um segundo momento, iremos organizar categorias de análise que recuperam a incidência terminológica do documento com o conteúdo e o discurso produzido para a implementação dessa política. A partir daí, cruzaremos os dados presentes no documento com as informações publicizadas pelos veículos oficiais do MEC que tratam do assunto.

\section{Empresariamento e mercantilização da educação pública}

Os estudos mais recentes acerca das políticas educacionais das últimas décadas (desde 1990) para o Ensino Superior, têm apontado um crescente projeto privatizante da educação superior, bem como, da transformação da educação como direito social em capital, seja na forma de mercadoria ou na forma de "valorização do valor". Na forma de mercadoria, quando se transforma em serviço a ser vendido e comprado por alguém diretamente, tal como o fazem as empresas educacionais privadas que vendem seus cursos de formação - presenciais ou a distância. E na valorização do valor quando o projeto fundamental da educação capitalista é produzir a mercadoria força de trabalho, na qual as diferentes e supostas modernas concepções agregam mais valor ao valor de troca dessa mercadoria. Daí se encaixam as concepções meritocráticas, empreendedoras, livres de contratos etc.

Como exemplos de tais estudos, temos Silva Júnior e Spears (2012, p. 5) que denunciam o fato de que o Ensino Superior está sendo reorganizado como uma mercadoria que atende as "demandas da economia política global contemporânea, definindo áreas de conhecimento prioritárias pelo governo federal brasileiro com valores de mercado diferentes, mas, de acordo com o seu valor estratégico e percebido". Assim como, Leher afirma que nas Instituições de Ensino Superior (IES) diferentes métodos de privatização são experimentados, em que

[...] a criação de condições legais para o livre fornecimento privado e para o direcionamento das instituições públicas para a esfera privada, por meio de fundações privadas, contratos, convênios com o setor empresarial, é tão ou mais importante do que a venda da participação estatal de um determinado setor. (LEHER, 2003, p. 8) 
Nesse bojo de discussões acerca das mudanças de sentido do Ensino Superior, Sguissardi et al (2003) vão afirmar que a educação tem passado por transformações de "direito de cidadania para um bem privado ou mercantil". Aprofundando a questão e seguindo essa pista deixada pelos autores, compreende-se que, de fato, está em curso um processo de transformação da educação em direção privatizante, porém, nos parece que a educação se transforma de "direito social para capital". Essa afirmação tem como base a elaboração de Fontes (2010a) sobre os processos intensificados de expropriações de direitos sociais e trabalhistas em prol de formas híbridas de imposição da lógica privada para a esfera pública, transformando direitos sociais em capital. Para a autora, a expropriação se trata

[...] da imposição [...] de uma lógica da vida social pautada pela supressão de meios de existência ao lado da mercantilização crescente dos elementos necessários à vida, dentre os quais figura centralmente a nova necessidade, sentida objetiva e subjetivamente, de venda da força de trabalho. (FONTES, 2010a, p. 88)

A neoliberalização da economia, cuja intensificação das privatizações metamorfoseou as relações entre a esfera pública e privada orientadas pelo mercado, se hibridizou em um novo fenômeno da internacionalização das economias nacionais (propagandeada de globalização) em que os mercados financeiros e a esfera produtiva, combinada com o avanço tecnológico, devoram os bens públicos, enfraquecem o Estado, as soberanias nacionais e implementam a ditadura do mercado em escala global.

Essa ditadura do mercado reorienta o caráter da propriedade coletiva para a esfera individual, cuja propriedade privada se torna o princípio regulador de todas as esferas da vida. Saúde, educação, segurança e outros não são mais direitos públicos e coletivos, são transformados em mercadorias a serem compradas e consumidas; é dizer que se transformam direitos e condições de existência em capital.

Essa compreensão da privatização como expropriação de bens sociais na atualidade, não diz respeito apenas à expropriação da terra, de forma absoluta, mas à "supressão das condições dadas da existência dos trabalhadores, e sua consequente inserção, direta ou mediada pela tradição, nas relações mercantis" (FONTES, 2010a, p. 89). A expropriação, portanto, opera como condição e decorrência das relações sociais 
capitalistas de produção, atravessada por diversas lutas sociais implementadas pela classe trabalhadora organizada.

Esses processos de expropriações não ocorrem sem interferência direta do Estado, seja na forma de proposições legais para a regulamentação de tais medidas ou mesmo na condução política da relação público-privado imposta à sociedade. Contraditoriamente, o Estado mínimo existente nas políticas orientadas pelo neoliberalismo é, ao mesmo tempo, máximo na implementação de tais orientações. Fontes, demarca que o papel do Estado nesse processo

[...] contrariamente ao apregoado, não para reduzi-lo, e sim para 'enxugar suas gorduras' (leia-se, eliminar direitos sociais) e remusculá-lo, torná-lo sarado e enxuto, em 'Estado pitbull', com o fito de defender o capital frente a eventuais ameaças da população. Tratou-se, portanto, de fortalecer o Estado para sustentar o capital, reduzindo todas as adiposidades que representavam as conquistas populares. (FONTES, 2010b, p. 17)

Nesse sentido, cabe ressaltar que as mudanças do governo federal ocorridas no ano de 2003, findando o governo de Fernando Henrique Cardoso (PSDB) - 1995 até 2002 - e iniciando o período petista (de Lula à Dilma) - 2003 até 2016, não trouxeram alterações substantivas no tocante à implementação de políticas privatizantes. Assim como, os governos de Temer (MDB) e Bolsonaro (sem partido) seguiram os ditames do assalto ao fundo público de forma acelerada, reajustando-os às suas políticas ultraliberais. O que se percebe é que há uma continuidade cada vez mais acentuada no direcionamento das políticas educacionais para a esfera privada, iniciada com FHC, atravessando os governos até a atualidade. Ao mesmo tempo, é preciso destacar também as descontinuidades dos governos supracitados que, embora tais diferenças sejam mais conjunturais do que estruturais, incorrem em processos híbridos de relação entre público e privado que vêm sendo chamados de "privatização não clássica", operando uma dupla forma de privatização: a) privatização clássica: em que o patrimônio público é completamente cedido (na forma de leilões, vendas ou concessões) para a iniciativa privada. Para citar alguns exemplos, temos o leilão do Pré-sal, aeroportos, rodovias, empresas estatais etc; b) privatização não clássica: criação de fundos ou empresas de direito privado que são apresentadas como modelos públicos de gestão - 
fundações e Organizações Sociais (OS) - porém permitem a possibilidade de entrada do capital privado aproveitando-se das políticas sociais, como por exemplo, a Fundação de Previdência Complementar dos Servidores Públicos Federais (FUNPRESP) e a Empresa Brasileira de Serviços Hospitalares (EBSERH).

Essas afirmações também podem ser ilustradas através de algumas medidas tomadas pela contrarreforma do Estado brasileiro em relação às políticas educacionais para o Ensino Superior, que apresentamos a seguir:

a) Relação entre IES e empresas privadas: duas legislações são expressivas nesse sentido, a Lei de Inovação Tecnológica (LIT) - regulamentada pela Lei 10.903, de 30 de dezembro de 2004 - e a contratação de Parcerias Público Privadas (PPP) - Lei 11.079, 30 de dezembro de 2004. Essas medidas regulamentam as parcerias entre as instituições científicas e tecnológicas, que englobam as universidades e institutos de pesquisa e as empresas privadas, estabelecendo formas de transferência de produtos e processos desenvolvidos nas IES objetivando nexos entre as políticas públicas de inovação e uma perspectiva de desenvolvimento econômico. Porém, ressalta-se que esse desenvolvimento tem por base a competitividade e o empreendedorismo da economia brasileira. A concepção de inovação presente nessas medidas se refere à capacidade da produção científica e tecnológica de inserção no mercado, ou seja, o valor da pesquisa é medido pelo seu caráter pragmático de desenvolver o setor produtivo (em grande medida, o setor privado);

b) Financiamento do Ensino Superior privado: o Programa "Universidade para Todos" - PROUNI (Lei 11.096, de 13 de janeiro de 2005), criado pelo governo Lula (PT), surgiu sob o discurso de democratizar o acesso ao Ensino Superior com a ocupação de vagas ociosas nas Universidades privadas em troca de isenção de impostos - Imposto de Renda das Pessoas Jurídicas (IRPJ), Contribuição Social sobre o Lucro Líquido (CSLL), Contribuição Social para o Financiamento da Seguridade Social (COFINS) e Contribuição para o Programa de Integração Social (PIS) -, além de uma ampliação maciça dos empréstimos subsidiados pelo governo federal para os "clientes" através do FIES. Essa política tem uma clara intenção de beneficiar os empresários da educação, tendo em vista o elevado número de vagas sobrantes nas instituições particulares de ensino que, agora, passam a ser subsidiadas pelo governo federal. Demonstra-se, mais uma vez, a 
transformação da educação em capital sob "simpáticos" discursos de ampliar o número de estudantes que acessam o Ensino Superior;

c) Fundações estatais e empresas públicas de direito privado: criadas como mecanismos híbridos de integração público-privado, em que tais fundações e Organizações Sociais são utilizadas para captação de recursos através da prestação de serviços das IES ou mesmo de abrir possibilidades de cobrança para cursos de pósgraduação e serviços, por exemplo. March destaca que

[...] o tipo de propriedade, a forma de administração, a forma de controle e a gestão do trabalho no serviço público reproduzem a mesma lógica da área de atuação denominada de serviços sociais e científicos do Estado previstas no Plano Diretor da Reforma do Aparelho do Estado a ser desempenhada na época pelas organizações sociais e, no governo Lula, pelas fundações estatais de direito privado. (MARCH, 2012, p. 67)

Outra medida do governo federal, foi a criação da EBSERH, uma empresa pública de personalidade jurídica de direito privado que tem por intenção controlar os Hospitais Universitários. As IES são "convidadas" a aderirem à EBSERH através de contratos de adesão (nos moldes do REUNI) no qual se comprometem com metas de desempenho, indicadores e prazos de execução, cedendo todo o patrimônio dos Hospitais Universitários (HU) existentes para a EBSERH. Ou seja, ao aderirem à EBSERH, as IES abrem mão de seus HU que passam a ser administrados por conselhos da própria empresa, que permitirá o desenvolvimento de pesquisas e inovação sob os mesmos moldes das parcerias público-privadas. O caráter privatista é tão explícito que, na primeira versão do Programa Future-se, estava posta a permissão para que os HU atendessem usuários com planos de saúde privados, favorecendo quem paga em hospitais públicos, prática bem distinta da política de atendimento público e universal do Sistema Único de Saúde (SUS).

A política educacional que se torna síntese do projeto privatista é o Plano Nacional de Educação (PNE) 2014-2024 - Lei 13.005/2014 (BRASIL, 2014) - que aponta metas para a educação que fortalecem o setor privado da Educação Infantil ao Ensino Superior. Ilustramos através da Meta 12, presente no PNE, com o seguinte teor: 
Elevar a taxa bruta de matrícula na educação superior para 50\% (cinquenta por cento) e a taxa líquida para 33\% (trinta e três por cento) da população de 18 (dezoito) a 24 (vinte e quatro) anos, assegurada a qualidade da oferta e expansão para, pelo menos, 40\% (quarenta por cento) das novas matrículas, no segmento público. (BRASIL, 2014, p. 6)

Tal Meta, para ser atingida, deverá implementar a seguinte estratégia: “12.6) expandir o financiamento estudantil por meio do Fundo de Financiamento Estudantil FIES [...] com a constituição de fundo garantidor do financiamento, de forma a dispensar progressivamente a exigência de fiador" (BRASIL, 2014, p. 6).

Ao afirmar que a ampliação do acesso ao Ensino Superior se dará apenas em 40\% das instituições públicas e que essa ampliação se dará na forma da expansão de recursos no FIES, fica explícito que as iniciativas governamentais concentram-se no acréscimo da inserção privada na educação superior custeada pelo orçamento público através do financiamento estudantil.

Assim caracterizado pela expansão das instituições privadas de ensino superior com potente apoio do Estado em políticas e repasse de recursos públicos, o avanço do empresariamento da educação se consolida como a forma hegemônica de Ensino Superior. De acordo com os dados do Censo da Educação Superior (INEP, 2017), em 2017 o Brasil tinha 296 IES públicas e 2.152 privadas, o que representa $87,9 \%$ da rede. Esse percentual de instituições privadas tem aumentado sistematicamente a cada nova divulgação do Censo da Educação Superior, potencializado por programas como PROUNI e FIES já abordados anteriormente e, mais recentemente, com a expansão de certificações por parte do MEC de empresas educacionais que operam através de Educação a Distância (EaD) na oferta de cursos de graduação e pós-graduação.

Para além das diferentes formas de privatização explicitadas, é preciso compreender que junto a esse processo, temos também um projeto educacional em curso que, determinado pelo mercado, produz subjetividades na formação profissional que envolvem capacidades - chamadas de competências - que fortalecem processos de alienação da mercadoria força de trabalho. Os ideais/slogans propagados como empreendedorismo, empregabilidade, competências etc. vão reforçando um certo disciplinamento do profissional em meio a um contexto de retirada de direitos que forja 
profissionais habilitados para operarem em um mercado cheio de instabilidade e incertezas.

A compreensão do disciplinamento como uma categoria fundamental na relação entre trabalho e educação passa por entender que esta "configura-se como uma transformação intelectual, cultural, política e ética, uma vez que tem por objetivo o desenvolvimento de uma concepção de mundo tão consensual quanto seja possível, tendo em vista as necessidades de valorização do capital” (KUENZER, 2005, p. 82). Esses aspectos do disciplinamento se definem como estruturantes de uma subjetividade que interessa aos mecanismos de exploração e aceitação impostos pelo modelo de produção atual.

O papel dos processos educativos, mormente a formação técnicoprofissional, qualificação e requalificação, neste contexto, é de produzir cidadãos que não lutem por seus direitos e pela desalienação do e no trabalho, mas cidadãos participativos, não mais trabalhadores, mas colaboradores e adeptos ao consenso passivo e [...] tornarem-se déspotas de si mesmos. (FRIGOTTO, 2005, p. 48)

A subjetividade disciplinada encontra a sua relação articulada com a objetividade das competências a serem ensinadas e apreendidas pelos estudantes; essa objetividade estamos chamando de "empregabilidade", assim como o fazem Gentili (2005) e Frigotto, Ciavatta e Ramos (2005), cuja noção se insere num processo de superação da teoria do capital humano, no que diz respeito à garantia de inserção no mercado de trabalho com melhores qualificações através da formação. Superada, não porque não exista mais, mas porque sua forma original se modificou na medida em que vivemos um período de desemprego estrutural em que mesmo a mão de obra mais qualificada não encontra possibilidades garantidas de inserção ao emprego.

Portanto, a empregabilidade é trazida como uma necessidade individual de aquisição de competências para a disputa por emprego, não representando, como defendiam os teóricos do capital humano, que o crescimento econômico de determinado país dependesse do nível de qualificação dos trabalhadores e das trabalhadoras, e muito menos que o investimento individual em formação e treinamento garanta algum tipo de retorno futuro. A tendência de diminuição do trabalho vivo na produção tem reduzido o 
número de empregos, mas com uma necessidade complexa de capacidades para produção flexível, mas não necessariamente "qualificada".

Também aqui se destaca a noção de "empreendedorismo" tão presente nas recentes políticas educacionais que está atrelada a esse projeto educacional que intensifica as formas de exploração e super-exploração do trabalho. Empreender é uma palavra que busca maior aceitação na formação profissional quando é acompanhada de noções de criatividade, inovação, colaboração, atualização, oportunidades etc. Porém, no fundo, o empreendedorismo vai significar um conjunto de iniciativas formativas que visam profissionais atuando em contextos inseguros e sem garantias, com baixa remuneração pelo trabalho, com ampliação da transformação de pessoas físicas em pessoas jurídicas, com prestação de serviços ao invés de desenvolvimento laboral, e outras formas precárias de colocar-se no mercado de trabalho.

\section{Future-se: análise documental do programa}

Neste tópico, trataremos de analisar o projeto Future-se apresentado pelo MEC. Utilizando as palavras/termos que entendemos como sendo aqueles de mais forte sentido às demandas do capital e que direcionam o texto contido no documento para o empresariamento da educação pública, ou seja, aqueles termos que retratam os fundamentos da política apresentada no projeto Future-se.

Desse modo, compreendemos que as palavras utilizadas apresentam sentidos produzidos para determinados grupos econômicos e políticos, neste caso, percebemos uma demanda ao grupo empresarial, palavra que vem já apresentada como um dos eixos do projeto através do empreendedorismo, entre outras que destacaremos aqui.

Para melhor desenvolver a análise de dados, apresentamos aqui uma tabela com os termos/palavras-chave encontrados no texto que, em síntese, demonstram o direcionamento de caráter empresarial dado à educação pública. O Quadro1, elaborado a partir do documento do Future-se, nos permite compreender o direcionamento do projeto, em suas determinações mercadológicas; são termos que regem os pontos centrais da tentativa de um projeto de mercantilização da educação pública. 
Quadro 1-Termos/Palavras-Chave encontrado no Projeto Future-se

\begin{tabular}{|c|c|c|}
\hline Palavras-Chave & $\mathbf{N}^{\circ}$ & Descrição da utilização da Palavra-Chave \\
\hline $\begin{array}{l}\text { Empreendedorismo; } \\
\text { Empreendedor; } \\
\text { Empreendedores; } \\
\text { Empreendedora }\end{array}$ & 16 & $\begin{array}{l}\text { Enquanto a divisão de seus eixos; enquanto ao destino de seu } \\
\text { fundo patrimonial; enquanto diretrizes do eixo pesquisa, } \\
\text { desenvolvimento tecnológico e inovação; enquanto eixo } 2 \text { e } \\
\text { diretrizes; enquanto atividades nas matrizes curriculares; enquanto } \\
\text { promoção a ações; enquanto ecossistema nacional; ações ligadas à } \\
\text { assistência estudantil; enquanto perfil; ao se referir a institutos } \\
\text { empreendedores; referindo-se à visão e à educação }\end{array}$ \\
\hline Privado; Privada & 13 & $\begin{array}{l}\text { Referindo-se a direito público e privado; sobre negociação entre } \\
\text { universidades e institutos federais com entes privados; trabalho } \\
\text { privado. Referindo-se a FP - Future-se com ativos de natureza } \\
\text { privada; a organização gestora do Fundo Patrimonial do Future-se } \\
\text { será instituição privada sem fins lucrativos; o Fundo Soberano do } \\
\text { Conhecimento terá natureza privada; universidades privadas }\end{array}$ \\
\hline Empresa (s) / Empresarial & 13 & $\begin{array}{l}\text { Startup - empresa emergente; facilitação de parcerias entre o setor } \\
\text { privado e o público prestação de serviços; objetivo de atender } \\
\text { demandas de empresas; assim como as necessidades do setor } \\
\text { empresarial e do contexto regional, com o objetivo de direcionar as } \\
\text { ações da política de inovação; parceria com o setor empresarial; } \\
\text { organização das associações denominadas empresas juniores; } \\
\text { estimular empresas inovadoras; contratação de empresas juniores; } \\
\text { valores negociados pelas universidades e institutos federais com } \\
\text { empresas que excedam o previsto para a execução de projetos }\end{array}$ \\
\hline Educação & 1 & Promoção e disseminação da educação empreendedora \\
\hline Mercado & 5 & $\begin{array}{l}\text { Multimercado; necessidade do mercado; mercadorias ou mercado } \\
\text { de balcão }\end{array}$ \\
\hline Desempenho & 16 & $\begin{array}{l}\text { Relacionado a contrato de desempenho; indicadores de resultados; } \\
\text { avaliação das universidades; mensuração do desempenho; } \\
\text { estudantes com alto desempenho }\end{array}$ \\
\hline
\end{tabular}

$\mathrm{N}^{\circ}$ : quantidade de vezes que aparece a palavra.

Fonte: Elaborado pelos autores, 2020.

Para que possamos iniciar a análise, precisamos compreender que o sistema capitalista é um sistema que se encontra em crise, e é nessas crises que ele busca se reconfigurar para ter mais um sopro de vida. Reconfiguração essa que aprofunda as determinações exploratórias do capital sobre os trabalhadores e trabalhadoras. Druck (2013) salienta que a precarização do trabalho esteve bastante presente no Brasil desde a passagem do modo de produção escravista para o trabalho assalariado, mesmo que, segundo a autora, se considere que no Brasil exista uma nova forma de precarização social do trabalho, que se configura como "nova" pois se modifica e amplia causando os 
retrocessos dos ganhos sociais duramente conquistados pela população que vive do seu trabalho.

Assim, o sistema capitalista durante seu percurso histórico sofreu transformações, de tal modo, que não se estrutura como elemento fixo perante a sociedade, mas está em constante desenvolvimento, todavia continua como um sistema em que as "relações sociais se assentam sobre o trabalho assalariado, ou seja, pela apropriação do trabalho pelo capital, através da compra e venda da força de trabalho no mercado, independentemente das formas de contrato existentes ou predominantes" (DRUCK, 2011, p. 41).

Para que se estabeleçam as demandas de exploração do trabalho, é necessário um sistema educacional que corresponda a essas expectativas mercadológicas, tanto a nível básico, quanto superior. Desse modo, a educação irá submeter-se a garantir as funções específicas na sociedade capitalista. Essas funções específicas, segundo Mészáros (2006, p. 275-276), são:“ (1) a produção das qualificações necessárias ao funcionamento da economia, e (2) a formação dos quadros e a elaboração dos métodos de controle político. [...] Por isso a crise da educação se manifesta com vigor tanto no plano econômico como político".

As políticas públicas educacionais trazem consigo profundas mudanças nas formas como se estabelece o sistema educacional e, consequentemente, para os trabalhadores e trabalhadoras dessa área, como também para alunos e alunas. Na década de 1990, as reformas do Estado trouxeram um aprofundamento na precarização do trabalho docente e estabeleceram um princípio de gerencialismo; nesse sentido, o Estado se exime de ser fornecedor de serviços para assumir um papel de gerenciador das políticas pública que podem ser aplicadas pelo setor privado. Assim, esse modelo se caracteriza pela “descentralização de responsabilidades, ao lado da centralização do controle sobre questões estratégicas como formulações das políticas docentes, currículo e da avaliação." (BACCIN; SHIROMA, 2016, p. 130).

O modelo gerencialista reconfigura as obrigações que antes eram do Estado e dissemina tais responsabilidades para os indivíduos e para as corporações. Também é necessário compreender que o Estado gerencialista tende à diminuição dos 
investimentos públicos e apresenta um modelo de avaliação dos serviços por desempenho, que se torna fundamental na esfera educacional (LIMA; GANDIN, 2012).

A palavra desempenho aparece 16 vezes na minuta do projeto Future-se, se relacionando às possibilidades de mensuração deste desempenho estabelecidos em contratos. Podemos observar isto nos trechos que destacamos abaixo:

I - contrato de desempenho: instrumento jurídico celebrado entre universidades ou institutos federais e a União, por intermédio do Ministério da Educação, caracterizado pela consensualidade, objetividade, responsabilidade e transparência, com a finalidade de estabelecer indicadores de resultado para a contratante, tendo como contrapartida a concessão de benefícios especiais;

III - indicadores de resultado: referenciais utilizados para avaliar o desempenho da universidade ou do instituto federal;

Art. $5^{\circ} \mathrm{A}$ participação no programa Future-se fica condicionada à celebração, no prazo de doze meses, contados a partir da entrada em vigor desta Lei, de contrato de desempenho, nos termos do $\S 8^{\circ}$ do art. 37 da Constituição, a ser firmado entre a universidade ou o instituto federal e o Ministério da Educação.

Art. $6^{\circ} \mathrm{O}$ contrato de desempenho será celebrado entre a universidade ou o instituto federal e o Ministério da Educação, tendo como contrapartida a concessão de benefícios especiais.

Art. $7^{\circ} \mathrm{O}$ Ministério da Educação, conjuntamente com a universidade ou o instituto federal, fixará os indicadores para mensuração do desempenho relacionados aos eixos do Programa, considerando as peculiaridades de cada instituição. (MEC, 2019, pp. 2-4)

Esses trechos remetem ao contrato de desempenho e os indicadores de mensuração desse desempenho que serão estabelecidos entre o MEC e as instituições que fizerem parte do projeto Future-se. Igualmente, no site do MEC, temos algumas explicações sobre o projeto; em um dos tópicos (pesquisa e inovação), podemos perceber o direcionamento da educação pública ao setor privado, para o desenvolvimento do polo empreendedor, como segue:

- instalar centros de pesquisa e inovação, bem como parques tecnológicos;

- assegurar ambiente de negócios favorável à criação e consolidação de startups, ou seja, de empresas com base tecnológica;

- $\quad$ aproximar as instituições das empresas, para facilitar o acesso a recursos privados de quem tiver ideias de pesquisa e desenvolvimento; 
- $\quad$ premiar os principais projetos inovadores, com destaque para universidades e institutos que tiverem melhor desempenho, respeitada as condições inicias e especifidades de cada um. (MEC, 2019, p. 1)

Os medidores criados para a mensuração da qualidade educacional surgem como mecanismos de controle, desenvolvidos através de políticas pública liberais que visam analisar a qualidade educacional Podemos dar como exemplo o Índice de Desenvolvimento da Educação Brasileira (IDEB), que visa observar o desempenho dos estudantes das escolas públicas e, consequentemente, dos agentes escolares, porém o que realmente fazem tais políticas é apontar culpados para problemas que são desenvolvidos nas margens do sistema capitalista, seguindo um lógica meritocrática (SILVEIRA, 2019). Nesse caso, entendemos que a palavra desempenho remeta, não às melhores condições e formas de ensino, mas a suprir as demandas empresariais.

Os elementos que circundam diversos textos que propõem políticas públicas para a educação, vêm repletos de slogans que servem para enfeitar as propostas e colocar ao público o caráter de necessidade e eficiência das medidas, bem como naturalizá-las no cotidiano, gerando aceitação e encontrando apoio na sociedade, criando "consentimento ativo" (descrito por Shiroma e Santos utilizando como base Gramsci e Harvey em obra já citada anteriormente). Pois, tais medidas só podem funcionar de forma adequada com as “[...] determinações educacionais gerais da sociedade como um todo [...] Aqui a questão crucial, sob o domínio do capital, é assegurar que cada indivíduo adote como suas próprias as metas de reprodução objetivamente possíveis do sistema." (MÉSZÁROS, 2008, p. 43-44). No caso da educação, esse processo de aceitação social acaba por direcionar os docentes e a

[...] comunidade escolar à adoção de novas práticas: a) mudanças culturais na gestão educacional; b) maior participação da comunidade nas atividades escolares, em muitos casos, restrita ao auxílio financeiro; c) mudança significativa nas políticas de acompanhamento da aprendizagem focadas em avaliações de desempenho em escala nacional; d) descentralização; e) incorporação de conceitos como participação, eficiência, eficácia como indicadores da qualidade na educação. (SHIROMA; SANTOS, 2014, p. 22) 
Elementos facilmente encontrados no projeto Future-se. O projeto propõe que as universidades busquem financiamento próprio ficando, assim, mais independentes do orçamento público. A chamada sustentabilidade financeira para as universidades, que exige das instituições de ensino arrecadarem subsídios, auxiliaria na estabilidade financeira ao fixar limites de gastos com pessoal, já que, conforme a explicação do MEC em seu site, até então, dentro do orçamento destinado às instituições, $85 \%$ são destinados para gastos com pessoal.

Desse modo, compreendemos que um dos interesses com esse projeto seja a diminuição de gastos com pessoal, necessário ao bom funcionamento das universidades e institutos federais. Se já não bastasse o contingenciamento de gastos feito pela implementação da Emenda Constitucional 95/2016, que congela os gastos educacionais por 20 anos, as universidades e institutos federais precisam promover-se de modo a garantir sua sustentabilidade financeira buscando recursos fora da esfera da União, captando no mercado através de fundos ou da venda de serviços.

O projeto também utiliza da comunidade acadêmica quando menciona o empreendedorismo e atuações no núcleo de inovação tecnológica, o que remete à participação da comunidade, porém a captação de recursos fica, como mencionado anteriormente, a cargo das instituições, o que descentraliza a responsabilidade do Estado sobre o repasse de verbas para, neste caso, a área educacional.

O projeto também estabelece formas de avaliação de desempenho nos contratos estabelecidos, porém não especifica como irá fazer essa mensuração, no entanto, explica que é algo a ser estabelecido com as instituições; ainda, menciona a possibilidades de bolsas para estudantes com alto desempenho e/ou para atletas. Nesse ponto, vale ressaltar que a concessão de bolsas para estudantes de alto desempenho, além de não ser especificado o que é considerado de alto desempenho, ainda pode acabar por desfavorecer os estudantes de baixa renda que não possuem condições estruturais para permanecerem nas instituições de ensino e necessitam das bolsas para se manterem e, assim, conseguirem melhorar seus currículos.

Essa forma de estabelecer um direcionamento ao entes privados com engajamento da sociedade e de divisão de responsabilidades, apela para palavras-chaves que possam chamar a atenção e a aceitação. Palavras como empreendedorismo, 
empreendedores, empreendedora, empreendedor, empresa(s)/empresarial (que, somadas, aparecem 29 vezes ao longo do texto), mercado (5), desempenho (16), estabelecem um vínculo mercadológico com a educação na medida em que estabelecem elementos para facilitar a entrada no mercado empresarial dentro da instituições, por meio de laços contratuais e financiamentos público-privado. Esse ponto fica explícito logo no primeiro artigo do referido projeto em que diz:

Art. $1^{\circ}$. Fica instituído o Programa Universidades e Institutos Empreendedores e Inovadores - Future-se, que tem por finalidades:

I - propiciar fontes adicionais de financiamento para as universidades e institutos federais;

II - incentivar o incremento da captação de recursos próprios;

III - viabilizar a destinação dos recursos próprios diretamente para a respectiva universidade ou instituto federal; IV - promover e incentivar o desenvolvimento científico, a pesquisa, a capacitação científica e tecnológica e a inovação;

$\mathrm{V}$ - fomentar a promoção da visão empreendedora; e $\mathrm{VI}$ - estimular a internacionalização das universidades e institutos federais. (MEC, 2019, p. 1)

A lógica de mercado estabelece a necessidade da produtividade, direcionada ao setor público, ou seja, deve-se estar sempre empreendendo e inovando, com o menor custo de produção possível. Nesse processo, estabelece um direcionamento para a formação de discentes preparados para o mercado de trabalho capitalista, tudo isso

[...] em estreita relação entre professores, alunos, Organizações Não Governamentais (ONG) especializadas em incentivar $\mathrm{O}$ empreendedorismo, empresários, entre outros agentes. Mesmo que o assunto possa causar alguns questionamentos, é cada vez maior o número de escolas que se propõe a ensinar como seus alunos podem sobreviver no mundo capitalista, oferecendo atividades curriculares voltadas para a formação de empreendedores. (COAN, 2014, p. 142)

A formação para o mercado parece ser ponto central do projeto. Observamos que um de seus pontos diz respeito ao seu artigo primeiro em seu inciso quinto, " $V$ - fomentar a promoção da visão empreendedora". Além da "visão empreendedora", as instituições educacionais terão que se preocupar com um ranking que apontará as universidades e instituições federais mais eficientes nos gastos e que ganharão prêmios por conta disso. Esses elementos podem causar deficiências ou diferenças de como as instituições irão 
priorizar recursos para os cursos de formação. Pois se o projeto tem por finalidade a produtividade econômica de mercado e a "qualidade" avaliada é sua potencialidade de retorno financeiro, é possível que determinadas áreas do conhecimento e campos de atuação profissional sejam cada vez mais escasseados. Para ilustrar: nas Ciências Agrárias, o modelo do agronegócio e da grande extensão de terra é a referência para a formação universitária no projeto de educação capitalista, portanto, perguntamos se nesse projeto haverá alguma possibilidade de investimentos e boa avaliação em cursos que tenham como objetivos a agroecologia, produção orgânica e economia solidária? Assim como as ciências humanas e sociais, cuja produção não necessariamente tenha retorno financeiro diretamente do mercado. E outros campos do conhecimento que seriam prejudicados por tal projeto.

No que se refere ao projeto Future-se, a lógica de estreitamento com o setor privado se estabelece em parcerias mais flexibilizadas, que são negociadas diretamente com as universidades e institutos federais, como é ressaltado em seu artigo 17, em que se refere ao PD\&I, ou seja, Pesquisa, ao Desenvolvimento Tecnológico e à Inovação.

O artigo expressa o seguinte

Art. 17. As universidades e institutos federais poderão negociar com entes privados valores além daqueles previstos para a execução dos projetos de PD\&l, os quais deverão ser integralizados nos fundos patrimoniais previstos nesta Lei. (MEC, 2019, p. 9)

Aqui já estabelecemos outra palavra-chave que utilizamos em nossa análise do documento: Privado/Privada, que soma 13 vezes no decorrer do texto, ao se referir à Sociedade de Propósito Específico (SPE), em seu artigo $2^{\circ}$ e inciso $8^{\circ}$, apresenta a possibilidade de "pessoa jurídica de direito privado, com a participação de pessoas físicas ou jurídicas, privadas ou públicas, criada com a finalidade de desenvolver projeto específico, com prazo determinado e limitado ao término do objeto da sociedade." (MEC, 2019, [p. 2]). Deste modo, as SPE trabalhariam articuladamente com as universidades e com os institutos federais, facilitando os laços empresariais na educação. O projeto prevê a facilitação das parcerias com o setor privado, para atender as demandas das empresas, como segue no artigo 16 que apresenta as diretrizes dos eixos, em seu inciso primeiro. 
I - facilitar meios de acreditação de infraestruturas de pesquisa junto às entidades e órgãos competentes, para a realização de parcerias ou para a prestação de serviços técnicos especializados com empresas e demais instituições que integram o Sistema Nacional de Ciência, Tecnologia e Inovação. (MEC, 2019, p. 8)

As mudanças empregadas às universidades e institutos federais vêm por meio de sucessivos processos de privatizações (mesmo sendo através de direcionamento de recursos para o setor privado) e mercantilização da educação. A produtividade e o custo benefício vêm a priori da qualidade educacional. Desse modo, o produtivismo no âmbito da educação vem através de políticas mercantilizadoras, ou seja, dando um valor econômico à educação. Assim, o Future-se se torna um projeto que direciona "um modelo excludente que transforma a educação num recurso privado e a escola num locus instrumental do mercado." (PALMEIRA SOBRINHO, 2019, p. 64).

O projeto Future-se tenta aumentar a lógica de mercado (palavra que aparece cinco vezes no texto) para a educação. A palavra mercado aparece relacionando-se a elementos como multimercado, explicando o Fundo Soberano do Conhecimento (FSC), que visa integralizar ativos financeiros com o intuito de geração de receitas, também quando se refere ao fomento de projetos de pesquisa que estimulem a criação de startups e que atendam as demandas de mercado. Outro ponto, dentro desses elementos, são as possibilidades de negociações centralizadas e eletrônicas, no mercado de bolsas de valores e no mercado de balcão (fora da bolsa de valores). O Future-se, mexe com a estrutura das instituições de ensino, focando na lógica de mercado e dos interesses das empresas privadas.

Porém, ao elaborar o projeto, se esquece do principal elemento de sua elaboração, a educação, que foi encontrada apenas uma vez no documento, sendo que em sua maioria referindo-se a complementos de tópicos, por exemplo, as vezes em que podem ser encontradas são referentes ao MEC ou à Lei de Diretrizes e Bases da Educação Nacional (LDBEN) e suas leis, e complementação quando se refere às instituições públicas relacionadas à educação e à viabilidade de uma educação sustentável. A palavra educação no documento é apresentada da seguinte forma: 
Art. $18^{\circ}$. Constituem diretrizes do eixo de empreendedorismo: [...] $\mathrm{VI}-$ promoção e disseminação da educação empreendedora por meio da inclusão de conteúdos e atividades de empreendedorismo nas matrizes curriculares dos cursos técnicos, de graduação e de pós-graduação, nos termos da política institucional de inovação. (MEC, 2019, p. 9)

Desse modo, essa é a única vez que a palavra educação é apresentada no projeto de forma mais específica, já que se estabelece de forma geral mesmo não deixando claro os elementos pedagógicos que iriam reger os aspectos educacionais, deixando essa parte para o artigo 16 no inciso $3^{\circ}$ em que menciona a capacitação da comunidade acadêmica, remetendo não a elementos de formação dos respectivos cursos, o que levaria aos aspectos educacionais formativos de cada cursos de suas respectivas instituições, mas no que se refere à inovação tecnológica. Mais uma vez direcionado não para uma educação que forme para o desenvolvimento humano, mas para atender as demandas de desenvolvimento do capital.

\section{Conclusão}

Ao longo do desenvolvimento do sistema capitalista, diferentes formas de exploração do trabalho vão sendo implementadas buscando superar as crises cíclicas. Assim, se estabelecem tensionamentos dentro da sociedade; nesse processo aprofundase a exploração da vida. O sistema capitalista encontra novos caminhos em busca da intensificação do trabalho como forma de garantir as demandas de mercado e, assim, se encarrega de apresentar essas demandas de maneira que consiga a aceitação popular. Utiliza-se do discurso do empreendedorismo, no individualismo, na falácia da meritocrática, tudo para jogar no colo da população os problemas inerentes a esse sistema.

Entendemos que o projeto Future-se é mais uma das formas de precarização do ensino público, neste caso das universidades e institutos federais e, consequentemente, da precarização do trabalho. O projeto apresenta uma política pública para essas instituições de ensino, porém focando centralmente no mercado. Desse modo, ao analisarmos os dados, foi possível identificar que dois conceitos-chave do projeto, inovação e empreendedorismo, se tornaram slogans das políticas educacionais capitalistas em meio à sua mais profunda crise. A partir dessas premissas e fundamentos, 
a análise sobre o programa passa, necessariamente, por compreender que há uma determinação explícita do mercado sobre a vida. Ao invés de pensar a educação voltada a enfrentar os problemas sociais, as demandas de vida da população e a formação humana de qualidade de cada sujeito, as políticas educacionais em curso definem os interesses empresariais, de lucratividade de poucos e as demandas econômicas como as bases fundantes dos projetos educacionais. O que se vê não é a educação contribuindo para a formação humana, é o mercado capitalista determinando as mercadorias humanas de que necessita.

Também foi possível observar que existe uma tendência do Estado, através de políticas públicas, a incorporar em sua gestão os fundamentos da iniciativa privada, estabelecendo modificações nas estruturas das instituições de ensino. Esse processo traz a ideia de que as universidades e institutos federais não estão funcionando em sua capacidade máxima e essas medidas seriam uma das respostas a esse e demais problemas. Também entendemos que as medidas de mensuração de desempenho tendem a reforçar a ideia de culpabilização, colocando o entendimento de que as demais instituições que não alcançam as determinadas pontuações, em algum tipo de ranking educacional, não o fazem por problemas específicos, sejam eles estruturais ou sociais, mas por falta de gestão.

O projeto Future-se compreende a educação como um valor de mercado, fazendo com que as instituições assumam como exemplo o caráter produtivista empresarial, estabelecido na lógica de mercado.

Assim, o projeto Future-se é mais uma política liberal que visa o aprofundamento da precarização educacional e laboral. Se estabelece através do estreitamento com o setor privado, naturalizando uma cultura hegemônica, desenvolvida na lógica do capital, que empurra para cima da classe trabalhadora os ditos do empreendedorismo. empreendedor de si mesmo surge como uma reformulação do sistema capitalista para dar conta de superar sua crise atual, assim as massas de trabalhadores e trabalhadoras são impelidas a acreditarem que seu sucesso depende única e exclusivamente de sua força de vontade. O projeto Future-se aplica a lógica empreendedora à educação pública de nível superior com o intuito de se eximir daquilo que entendemos como "gastos" e, ao 
mesmo tempo, abre as portas para que o setor privado possa investir e lucrar com a educação superior.

\section{Referências}

BRASIL. Lei n.13.005, de 25 de junho de 2014. Aprova o Plano Nacional de Educação - PNE e dá outras providências. Diário Oficial [da] República Federativa do Brasil, Seção 1, Brasília, DF, ano 151, n. 120 A, p.1 (ed extra), 26 de junho de 2014.

BACCIN, Eclea; SHIROMA, Eneida. O. A intensificação e precarização do trabalho docente nos institutos federais. Revista Pedagógica, Chapecó, v. 18, n. 39, p. 129-150, set./dez. 2016.

COAN, Marival. Educação para o Empreendedorismo como Slogan do Capital. In: EVANGELISTA, Olinda. (org.). O que revelam os slogans na política educacional. 1. ed. Araraquara: Junqueira \& Marin, 2014. 288 p.

DRUCK, Graça. Trabalho, precarização e resistências: novos e velhos desafios? Cad. CRH, Salvador, v. 24, n. especial 1, p. 37-57, 2011.

DRUCK, Graça. Precarização social do trabalho no Brasil: alguns indicadores. In: ANTUNES, Ricardo (org). Riqueza e miséria do trabalho no Brasil II. São Paulo: Boitempo, 2013.

FAIRCLOUGH, Norman. Discurso e mudança social. Brasília: Universidade de Brasília, 2001.

FONTES, Virgínia. O Brasil e o capital imperialismo: teoria e história. 2. ed. Rio de Janeiro: EPSJV; Editora UFRJ, 2010a.

FONTES, Virgínia. Novas encruzilhadas e velhos fantasmas. Prefácio. In: CASTELO, 
RODRIGO (org.) Encruzilhadas da América Latina no século XXI. Rio de Janeiro: Pão e Rosas, 2010b.

FRIGOTTO, Gaudêncio. Educação, crise do trabalho assalariado e do desenvolvimento: teorias em conflito. In: FRIGOTTO, Gaudêncio (org.). Educação e crise do trabalho: perspectivas de final de século. 7. ed. Petrópolis: Vozes, 2005. p. 25-54.

FRIGOTTO, Gaudêncio; CIAVATTA, Maria; RAMOS, Marise (org.). Ensino médio integrado: concepção e contradições. São Paulo: Cortez, 2005. p. 83-105.

FRIZZO, Giovanni. Crise do capitalismo, política ultraliberal e a extinção do ministério do esporte. Motrivivência, [Florianópolis], v. 31, n. 60, p. 01-15, out./dez. 2019. Disponível em: < https://periodicos.ufsc.br/index.php/motrivivencia/article/view/2175-8042.2019e67108>. Acesso em: 28 mar. 2020.

GENTILI, Pablo. Três teses sobre a relação trabalho e educação em tempos neoliberais. In: LOMBARDI, José Claudinei; SAVIANI, Dermeval; SANFELICE, José Luís. Capitalismo, trabalho e educação. 3. ed. Campinas: Autores Associados, 2005.

INEP - Instituto Nacional de Estudos e Pesquisas Educacionais Anísio Teixeira. Censo da Educação Superior. Brasília: INEP, 2017

KUENZER, Acácia. Exclusão includente e inclusão excludente: a nova forma de dualidade estrutural que objetiva as novas relações entre educação e trabalho. In: LOMBARDI, José Claudinei; SAVIANI, Dermeval; SANFELICE, José Luís. Capitalismo, trabalho e educação. 3. ed. Campinas: Autores Associados, 2005.

LEHER, Roberto. Projetos e modelos de autonomia e privatização das universidades públicas. Revista da ADUEL, [Londrina], n. 1, v. 1, p. 7-20 set. 2003.

LIMA, Iana; GANDIN, Luís. A. Entendendo o estado gerencial e suarelação com a educação: algumas ferramentas de análise. Práxis Educativa, [Santa Rosa], v. 7, n. 1, p. 6984, 28 jun. 2012.

MARCH, Cláudia. A empresa brasileira de serviços hospitalares, universidades públicas e autonomia: ampliação da subordinação à lógica do capital. Universidade e Sociedade, [Brasília], n. 49, 2012, p. 62-70.

MEC. Minuta de Projeto de Lei. [Brasília, DF]: Programa Universidades e Institutos Empreendedores e Inovadores - Future-se, 2019. Disponível em:

https://www.ufsm.br/wp-content/uploads/2019/10/Minuta-de-Anteprojeto-de-Lei-Futurese-GT-Portaria-1701-16-10-2019.pdf. Acesso em: 26 mar. 2020

MÉSZÁROS, István. 1930 - A teoria da alienação em Marx. tradução Isa Tavares. São Paulo: Boitempo, 2006.

PALMEIRA SOBRINHO, Zéu. FUTURE-SE. Revista FIDES, [Natal], v. 10, n. 2, p. 50-68, 12 nov. 2019. 
SGUISSARDI, Valdemar; CAMARGO, ELizabeth; PINO, Ivany; PACHECO, José; PIOZZI, Patrizia; GOERGEN, Pedro; OLIVEIRA, Romualdo. Educação: de direito de cidadania a mercadoria. Educação e Sociedade, Campinas, v. 24, n. 84, p. 727-732, set. 2003.

SHIROMA, Eneida; CAMPOS, Roselane Fátima; GARCIA, Rosalba Maria Cardoso. Decifrar textos para compreender a política: subsídios teórico-metodológicos para análise de documentos. Revista Perspectiva, Florianópolis, v. 23, n. 02, p. 427-446, jul./dez. 2005.

SHIROMA, Eneida; SANTOS, Fabiano. Slogans para a Construção do Consentimento Ativo. In: EVANGELISTA, Olinda (org.). O que revelam os slogans na política educacional. Araraquara, SP: Junqueira\&Marin, 2014.

SILVA JÚNIOR, João dos Reis; SPEARS, Eric. Globalização e Mudança do Papel da Universidade Federal Brasileira: uma perspectiva da economia política. Revista HISTEDBR On-line, Campinas, n.47, p.3-23 Set. 2012.Disponível em: <

https://periodicos.sbu.unicamp.br/ojs/index.php/histedbr/article/view/8640036>. Acesso em 26 mar. 2020.

SILVEIRA, Leonardo Lemos. Educação física e pobreza: a organização do trabalho pedagógico em um contexto de desigualdade social. 2019. 102f. Dissertação (Mestrado em Educação Física) - Programa de Pós-Graduação em Educação Física, Universidade Federal de Pelotas, Pelotas, 2019. 